\title{
INFÂNCIAS E CAIXAS: PANDORA ESPERANÇA
}

\author{
CHILDHOODS AND BOXES: PANDORA HOPE
}

Denise Marcos Bussoletti

Doutora em Psicologia pela PUC-RS. Docente do Programa de Pós-Graduação em Educação da UFPel.

Daniela da Cruz Schneider Mestranda em Educação pela UFPel.

Programa de Pós-Graduação em Educação Universidade Federal de Pelotas (UFPel)

Pelotas - RS - Brasil

Endereço:

Rua XV de novembro 1499

Centro - Pelotas - RS

CEP: $96015-000$

E-mails:

denisebussoletti@gmail.com danic_schneider@yahoo.com.br

RESUMO

Este artigo problematiza a infância em perspectiva alegórica, mediante um trabalho realizado no contexto da disciplina de Arte com crianças da 5a série de uma escola municipal, situada na periferia da cidade de Pelotas. O trabalho buscou uma aproximação entre a Arte Medieval e a Arte Contemporânea, explorando uma nova linguagem para expressão artística: interferência em um objeto do cotidiano, que passaria a ter função outra. Arte! O objeto suporte para a proposta foi uma caixa de sapatos. Oportunizou, ainda, uma reflexão com as crianças (e por meio delas) acerca da banalização da aparência, da busca de padrões em algo externo como sugestões para referenciar escolhas. Numa tentativa de síntese deste trabalho, propomos uma leitura por meio da aproximação da concepção de infância como crítica da cultura, uma "Infância Pandora”, em que as caixas produzidas pelas crianças revelam não só os nossos males e talvez também nossa esperança.

PALAVRAS-CHAVE: Arte. Infância. Banalização da Aparência.

ABSTRACT

This article investigates childhood from an allegorical perspective, through a work carried out in the context of the discipline of Art with children in the $5^{\text {th }}$ grade of a municipal school, located in the periphery of the city of Pelotas. The work searched for similarities between Medieval Art and Contemporary Art, exploring a new language for artistic expression: interference in an everyday object, which takes on another function. Art! The support object for the proposal was a shoebox. This work also promoted a reflection with (and through) the children, on the trivialization of appearance, and the search of standards in something external, as suggestions for referencing choices. In an attempt to summarize this work, we propose a reading through an approach to the concept of childhood as critic of culture, a "Pandora Childhood", in which the boxes produced by the children revel not only our problems, but perhaps also our hopes.

KEY WORDS: Art. Childhood. Appearance Vulgarizing. 
Walter Benjamin, em uma de suas passagens brilhantes, intitulada "Caixa de Letras", afirma que é impossível recuperarmos algo já absolutamente esquecido. E talvez não seja mau que as coisas assim sejam. Pois uma recuperação plena do passado poderia conter em si elementos de tal forma arrasadores que talvez ficássemos impossibilitados de compreender nossa saudade. I ronicamente, talvez só possamos abrangê-la quanto mais esquecida ela o for, quanto mais profundamente ela existir no esquecido. Como aquela palavra, que no esforço da lembrança parece impossível, pois, perdida, retornou para o seu lugar de sombra. Nisso, o esquecido contém em si o peso não só do que foi vivido, mas daquilo que ficou no prometido.

A "Caixa de Letras" benjaminiana possibilita, numa certa arqueologia temporal, esse encontro, e esse segredo, que nos faz sobreviver, em que pese "a poeira de nossas construções desmoronadas". A "Caixa de Letras" é uma das imagens da infância em Walter Benjamin, e do que ele considera como uma de suas maiores capacidades - o não esquecimento. Nessa perspectiva, cada lembrança da criança constitui-se numa parte, num fragmento, num gesto, num devir, em que o microcosmo contém em miniatura o destino e a promessa da utopia, lugar de re-encontro com seus aprendizados e sonhos.

A saudade que ela desperta em mim é a prova de como foi parte integrante da minha infância. O que, na verdade, procuro nessa relação é ela própria: toda a infância, tal como contida no gesto de enfiar as letras na calha onde se iriam ordenar em palavras. A mão ainda pode sonhar com esse gesto, mas nunca mais poderá acordar para o concretizar de fato. Assim, posso sonhar como uma vez aprendi a andar. Mas isso de nada me adianta. Hoje sei andar, aprender a andar é que já não sei. (BENJ AMIN, 1992: 153).

Neste texto, propor uma leitura da infância, aproximando a "Caixa de Letras" benjaminiana com a caixa mitológica de Pandora possui, inicialmente, essa compreensão. Uma tentativa de reencontrar pela infância nossos humanos gestos, transitando por entre imagens na lembrança e no esquecimento, na experiência e na promessa que como tal persiste e insiste em desafiar nossas im-possibilidades de compreensão.

Cabe ressaltar que neste artigo, ao pretendermos uma abordagem da infância, a qual esta é compreendida como um Outro do pesquisador-educador, apreendemos a escrita de pesquisa como uma resultante desse processo (BUSSOLETTI, 2007). Acatamos, para isso, a formulação de Marília Amorim (2001), na qual esta é uma prática por meio da qual a escrita e o conhecimento acontecem no diálogo vivido em campo e na relação com o outro do pesquisador. Tal dinâmica busca incorporar novas vozes e transformar os sentidos. A infância como esperança, pela arte e pela educação, é sobre isso que trataremos a seguir nessa breve reflexão.

\section{A CAIXA DE PANDORA}

A narrativa mitológica da Caixa de Pandora nos conta que Pandora foi um ser moldado em argila umedecida por Hefesto, atendendo a um pedido de Zeus, como uma forma de compensar pelo fogo roubado por Prometeu. A criação de Pandora aparece na mitologia como uma inovação, como um acréscimo: nenhum ser antes fora produzido desta forma. Inovação que envolverá todas as criaturas humanas, pois a partir de Pandora inaugura-se uma nova forma de vir ao mundo. A produção de Pandora implicou a consequência de que, daquele momento em diante, os seres humanos necessitariam reproduzir-se para existir. Zeus enviou Pandora como um presente a Epiteu, que mesmo sendo avisado por seu irmão, Prometeu para que não aceitasse presente algum vindo dos deuses, não resistiu, cedeu aos inúmeros encantos de Pandora e casou-se com a moça. Pandora trouxe do Olimpo em suas mãos, como presente de casamento ao marido, uma grande caixa que, ao ser por ela aberta, deixou escapar todos os males sobre a terra. Mesmo Pandora tentando fechar a caixa, foi inútil, todas as desgraças que até hoje nos assolam haviam sido libertas. A caixa ficou vazia, não fosse uma única exceção que permaneceu presa à sua borda - a esperança. A esperança surge, assim, como um antídoto, nessa narrativa mitológica que explica a origem de todos os males, trazida por aquela que "possui todos os dons".

Numa aproximação possível entre o mito e a história, podemos apreender a infância como esse lugar alegórico, como esse presente que por um lado revela encanto e também convida a revisitar 
nossas mazelas e incompletudes humanas, demasiadamente humanas. O que é, entretanto, uma alegoria? Rouanet nos diz que, "etimologicamente, alegoria deriva de allos, outro, e agoreuein, falar no agora, usar uma linguagem pública. Falar alegoricamente significa, pelo uso de uma linguagem literal, acessível a todos, remeter a outro nível de significação: dizer uma coisa para significar outra" (1984: 37). E do que nos fala a infância então? Que caixa é essa, cuja esperança propomos que seja compreendida como que "presa em suas bordas"?

Enste Bloch afirmou "o que importa é saber esperar" ainda que "pensar significa transpor" e que a esperança, como uma antecipação do futuro, é uma forma de conhecimento, um conhecimento daquilo que ainda-não-é; um conhecimento aberto em direção a um futuro que se ainda não o é como realizável, situa-se no plano dos "possíveis": o futuro de uma realidade presente, aqui traduzida como infância, ou como princípio da esperança. Quais seriam então os contornos desta atitude de espera? Bloch nos auxilia também nessa questão, reafirmando que esperar não significa resignar, pelo contrário, é um ato "apaixonado pelo êxito em lugar do fracasso", amplia em vez de estreitar, requer ação, nunca passividade, nem lástimas reconhecidas e tidas como intocáveis. É um "ato contra a angústia diante da vida e as maquinações do medo", ou, ainda, ele procura no próprio mundo aquilo que ajuda o mundo - isto é encontrável (1977: 14-15).

Concordamos com Larrosa quando afirma que o mundo apresentado pelas crianças estabelece um confronto com o mundo adulto, com nossos saberes e nossas práticas. E que por mais acúmulo que tenhamos nos vários campos do conhecimento (Psicologia, Pedagogia, Filosofia, etc...), "muitopouco" ainda sabemos sobre as crianças. A infância se estabelece assim, aos nossos sentidos, como um enigma constante e renovado. A infância acaba por questionar nossas certezas, tanto as certezas de mundo, como as que consideramos como próprias. A infância, por Larrosa, e desde Hannah Arendt, é um "acontecimento", algo que garante a "renovação do mundo e a descontinuidade do tempo"(LARROSA, 2000). Acatar a infância como um enigma, como um acontecimento, implica conceber a infância como um Outro, na perspectiva de um pensar e de um fazer em Psicologia e em Educação, articulando ética, estética e criação.

Acreditamos estar sendo fiéis ao princípio do dialogismo bakhiniano, no qual todas as vozes interessam, todas as vozes podem e devem ser ouvidas, e que dialogar não significa substituir ou justapor locutores, mas interagir sem a "imposição dogmática de uma única voz, nem o relativismo duma coexistência acrítica de todas as vozes, mas a síntese dialética das vozes contrárias" (FARACCO et al., 1988: 24).

Neste sentido, reafirmamos que a leitura deste texto é sugerida como uma abertura para e através da infância e suas caixas, alegoricamente concebidas. As caixas das infâncias, tal como a caixa de letras benjaminiana, se colocam assim, diante de nós, como sonho e como processo de criação. Passemos às caixas, então.

\section{CAIXAS E INFÂNCIAS: O CONTEXTO E A PROPOSTA EM DESCRIÇÃO}

O que envolve todas estas reflexões, bem como as próximas, ganha materialidade a partir de uma atividade pedagógica na disciplina de Arte, para uma turma de 5aㅗ série do Ensino Fundamental da Escola Municipal Núcleo Habitacional Dunas, no bairro Areal, da cidade de Pelotas/RS. Cabe ressaltar que a turma não corresponde aos padrões comumente encontrados em uma 5a série considerada regular. São crianças com histórias de vida que questionam todo estereótipo de infância hegemônico na sociedade. Vivem histórias muito distantes da fábula e dos encantos característicos de outras histórias que se contam para outras crianças, em outras realidades. Neste lugar periférico, mas nem por isso menos central, a infância ganha face multifacetada, distante da idealizada, mas uma infância real. Uma comunidade carente das mais diversas estruturas. Uma área esquecida pelos sucessivos governos, lembrada talvez e apenas como um símbolo ao contrário. I sto é, uma comunidade estereotipada pela marginalização. O espaço, sala de aula, não sedia alunos e a construção de conhecimento, somente. Nesta Escola, convive agressividade, resistências, afetos reprimidos... Talvez outros valores, no extremo oposto aos concebidos pelos centros de poder e saberes instituídos. A Escola firma-se sobre uma estrutura carente e bastante simples. Tem presença pontual na história do bairro, pois foi a primeira escola a ser construída. Une-se, desta forma, à construção do bairro e mistura-se à história de vida das pessoas que lá vivem. 
Neste contexto, o trabalho com essas crianças objetivou uma reflexão acerca da banalização da aparência, de como estamos constantemente buscando naquilo que é padrão, em algo externo, sugestões para referenciar nossas escolhas. Em termos gerais, propunha-se problematizar com a relativização dos conceitos de feio e de bonito. "O que é feio para um, não é feio para outro". Além disso, tentava uma aproximação entre a Arte Medieval e a Arte Contemporânea, bem como possibilitar uma nova linguagem para expressão artística com as crianças: um simples objeto, interferência em um objeto do cotidiano, que passaria a ter uma função outra... experiência com Arte!

I nicialmente, partimos da análise com as crianças sobre a premissa medieval de que a moral dos indivíduos e a sua submissão aos cânones da Igreja eram as verdadeiras riquezas de uma pessoa. Um culto que negava o corpo, considerado lugar de pecado. A proposta era sensibilizar, criar transparências e aproximar as visões de mundo da era medieval às das crianças do bairro em nossos dias.

Assim, foi preciso apreender como estas construções se deram na Arte, inserida na história. No primeiro momento foi realizada com as crianças uma leitura de obras de arte medieval, ressaltando a visão de mundo daquelas sociedades, a presença da Igreja na formação da subjetividade dos indivíduos e das formas como este contexto alterou a função da Arte. Esclarecemos, naquele momento, que a arte possuía uma função alfabetizadora, a partir da imagem, e buscava a afirmação de códigos morais, pleiteando a consolidação de uma nova ordem religiosa.

Propusemos, no segundo encontro, uma comparação, quando várias imagens de arte contemporânea foram levadas para a aula, com o objetivo de provocar inquietações e estranhamentos. A principal intenção era ampliar as possibilidades de se produzir arte, ou seja, apresentar diferentes modos de expressão, como instalações, performances, os próprios objetos (híbridos, entre esculturas, pequenas instalações, intervenção e apropriação). Este trabalho, dividido em dois momentos, ocorreu durante a primeira semana.

Na segunda semana, foram utilizadas imagens de propagandas publicitárias, buscando um paralelo ou um distanciamento das relações entre pessoas e a aparência, na idade média e na atualidade, chegando ao tema central da análise que seria trabalhada: ser bonito ou feio por fora e/ou por dentro. A pergunta era: O que é mais importante em nossos dias, o que somos por fora ou o que somos por dentro? E foi essa a provocação que invadiu a proposta. Como resposta... as crianças foram reafirmando que somos conquistados pelo exterior, compramos a aparência das coisas e dos objetos e estes se revestem de maior valor. Considerando isto, o desafio sugerido foi de que o objeto de arte construído pelas crianças pudesse ser desta forma afirmado: bonito por fora e feio por dentro. A proposta foi utilizar caixas de sapatos. Objetos que deveriam sofrer intervenção e alcançar a condição de objeto de experimentação artística e, ainda, abrigar o bonito no exterior, e o feio no interior. Solicitou-se que a caixa fosse trabalhada, na parte externa, de forma muito sedutora, que adquirisse uma aparência bonita, incitando o espectador a abri-la. Quando o fizesse, deveria deparar-se com o oposto, algo muito feio, que pudesse gerar alguma forma de desencanto. Para isso, as crianças poderiam servir-se de linguagens quaisquer (desenho, pintura, colagem, escrita, outros objetos), desde que houvesse intervenção e descaracterização da caixa de sapatos. O processo de construção das caixas ocorreu durante duas semanas, cada dia com dois períodos de aula.

Quando mencionamos os termos “objeto artístico", “objeto de arte”, não pretendemos afirmar que os trabalhos realizados pelas crianças possam caracterizar Arte. Apenas utilizamos os termos com a intenção de promover o distanciamento do que é de uso habitual (uma caixa) para, por meio de uma experimentação pela arte, conferir outro significado ao objeto. Infância e Arte aproximamse pela sua natureza de contravenção. Ambas têm a capacidade de contrariar poeticamente a objetividade da cultura, oferecendo um oposto de racionalidade outra.

\section{INFÂNCIAS, UNIVERSOS E CONCEPÇÕES: A ESCRITA DE PESQUISA EM CONSTRUÇÃO}

Um passeio em pulos... partindo da Arte Medieval, para as formas de relacionamento contemporâneas. As aproximações entre estes extremos, que vistos de forma linear parecem impossíveis, inscrevem-se na proposta da historiagrafia benjaminiana. Um projeto historiagráfico marcado pela centralidade de escrita da história que se dá por meio de imagens. Imagens de "sonho", "ambíguas" ou "arcaicas", despertadas num outro tempo, que não é o ontem, nem o 
amanhã, mas um tempo de um outro presente. Um tempo interrompido no espaço. Um tempo em que o presente se articula com o relevante do passado e o futuro anuncia sua proximidade. Um tempo benjaminiano anunciado, como aquele que distingue o tempo controlado pelos relógios do "tempo homogêneo e vazio"; neste, os acontecimentos caem dentro dele, do tempo pontuado pelo calendário, em que nos "dias de recordação" as coisas são relembradas e tornadas atuais. Esse é o tempo da história benjaminiano, não o das "badaladas indiferentes e regulares do relógio", mas antes o tempo da pausa, momento em que o passado como interpretação é construído e a história é o presente, o agora (BUSSOLETTI, 2007).

Uma proposta de experimentação de arte, que se origina nas ideias de interior e exterior, bonito e feio... e no que podemos apreender, por meio de Benjamin, como sendo a proposta de construção de um conhecimento sensível "que não apenas se alimenta daquilo que se apresenta sensível aos seus olhos, mas também consegue apoderar-se do simples saber e mesmo dos inertes como de algo experienciado e vivido" (TIEDEMANN, 2006: 18).

Se durante o medievo as apreciações voltavam-se para o interior, a atualidade impregna-se do oposto: a imagem de uma pessoa alcança nossas percepções antes de suas ideias. Vivemos em tempos de coisificação das subjetividades. Ou naquilo que reconhece Benjamin como um empobrecimento da experiência ou como uma nova barbárie (BENJ AMIN, 1994).

O suporte que sediou as concepções de belo e feio foi uma caixa de sapatos -- que acabou não se esgotando em sua transmutação. As simples caixas de sapatos, esquecidas em lugares outros, passaram a objetos de reflexão, mas somente após a intervenção de algumas infâncias em apreciação; uma proposição que colocou em discussão os valores para se pensar ensino de Arte, os valores que existem entre o feio e o bonito, pensar a infância como questionamento, como enigma, como acontecimento em revelação (LARROSA, 2000).

O envolvimento com esta proposta de trabalho dilatou-se para além do cumprimento da tarefa. Perceber que uma atividade tem seu fim nela mesma pode ser apenas um descaminho para pensar em si. Como ponderou Benjamin, caberia também aqui perguntar "[...] quando um poeta moderno diz que para cada um existe uma imagem em cuja contemplação o mundo inteiro submerge, para quantas pessoas essa imagem não se levanta de uma velha caixa de brinquedos?" ( BENJ AMIN, 2002: 102).

Fazer arte pressupõe desligamento, para uma re-conexão com outras instâncias criadoras de sentido. Este trabalho passou a ser um momento de se conectar com outras possibilidades, um outro estado de ser/estar. Foi mais do que simplesmente gostar; as crianças realizaram o trabalho como uma extensão delas mesmas, com sua singular apropriação. Experimentaram um espaço para dizer o que pensam sobre algo ser bonito ou feio, sem intervenções adultas como oposição, ou com uma assombrosa consonância de todas as coisas imateriais que cercam o lugar, em que elas, as crianças, habitam e resistem. O lugar sala de aula, de um bairro periférico, povoado de histórias nem sempre belas, mas também nem sempre tristes.

Quando as crianças foram interrogadas sobre quais materiais gostariam de usar, suas vozes foram unânimes: papel crepom, cola colorida, gliter... papel colorido... dourado. “Ah... e pode ser tinta também." Materiais, com exceção da tinta, que não foram utilizados nas aulas de Arte durante todo o ano escolar (a atividade ocorreu no final do último trimestre letivo), mas que fazem parte da cultura da escola. Na mistura de técnicas, um híbrido, algo que já não ganha mais conotações de pintura, escultura... Eis que surgem simplesmente as caixas... As caixas que pouco a pouco foram revelando o fascínio das crianças pelos objetos que podem ser considerados pela sociedade como lixo. As crianças, por meio das caixas, foram criando e possibilitando vias de acesso pela atividade ao mundo que é o delas. Buscaram a inversão dos critérios. Considerando que gosto sempre permeia discussões sobre Arte, seja na Escola, nas conversas informais ou, até mesmo, na universidade, cabe ressaltar que as crianças agiram por critério de gosto na seleção de suas imagens, tanto as que produziriam como aquelas que analisaram. Enfrentaram o que desacomoda. Na pauta pedagógica estava a necessidade constante de promover uma transposição deste patamar, possibilitar, a partir de estranhamentos com o mundo da arte, o desenvolvimento de apropriação das obras, de reconhecer a sua importância.

Bem, se até agora tratamos de tentar reconstruir um modo de a infância olhar, talvez coubesse, ainda, uma outra pergunta, sem necessidade de resposta imediata, apenas pontua uma atenta e necessária inversão de perspectiva: Como olhar esse olhar? Em que momento o professor, educador, pesquisador permite colocar em choque seus modos de ver? 


\section{AS CAIXAS: NOS LIMITES DA ESCRITA DE PESQUISA EM MANIFESTAÇÃO}
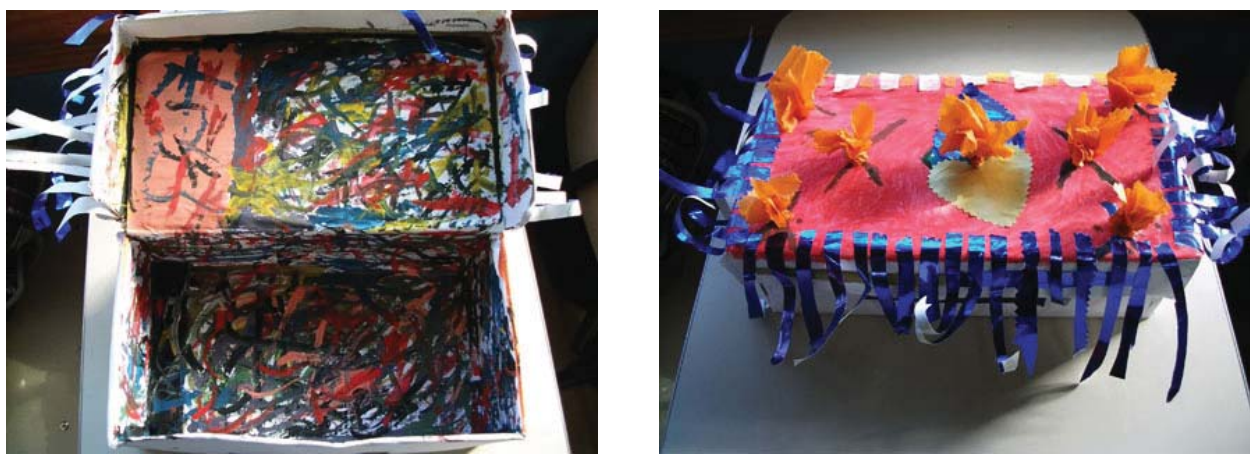

Franjas de Outra Ordem

Papel metálico azul profundo, tiras em franja. Flores laranja de papel crepom. Picote com tesoura de "franjinha"... um coração amarelo, outro azul. Um fundo vermelho... Esta caixa jamais caberia em uma sacola. O lugar dela é o da contemplação. E, ao se pretender visualizar o interior, todo o cuidado é pouco... Dentro, a bagunça. Recorrente a abstração aparecer como elemento da ordem do feio. Ela materializa a bagunça, uma profusão de cores e gestos condensados em linhas... o caos sempre desacomoda o olho... a necessidade do mundo adulto é de pôr ordem nas coisas... a necessidade da criança é de convidar a essa outra forma de orientação. Franjas como adorno daquilo que demarca um sentido diferente ao da ordem adulta do mundo e das coisas. Pela ação da criança tudo acontece em sua "floresta de sonhos". Pelas linhas e entrelinhas um confronto entre a ordem adulta e a ordem infantil. Por Benjamin, o que poderia ser "pôr em ordem" essa outra forma de orientação.

Pôr em ordem" significaria aniquilar uma obra repleta de castanhas espinhosas, que são as clavas medievais, papéis de estanho, uma mina de prata, blocos de madeira, os ataúdes, cactos, as árvores totêmicas e moedas de cobre, que são os escudos. A criança já ajuda a muito tempo no armário de roupas da mãe, na biblioteca do pai, enquanto que no próprio território continua sendo o hóspede mais instável e belicoso (BENJ AMIN, 2002: 107).

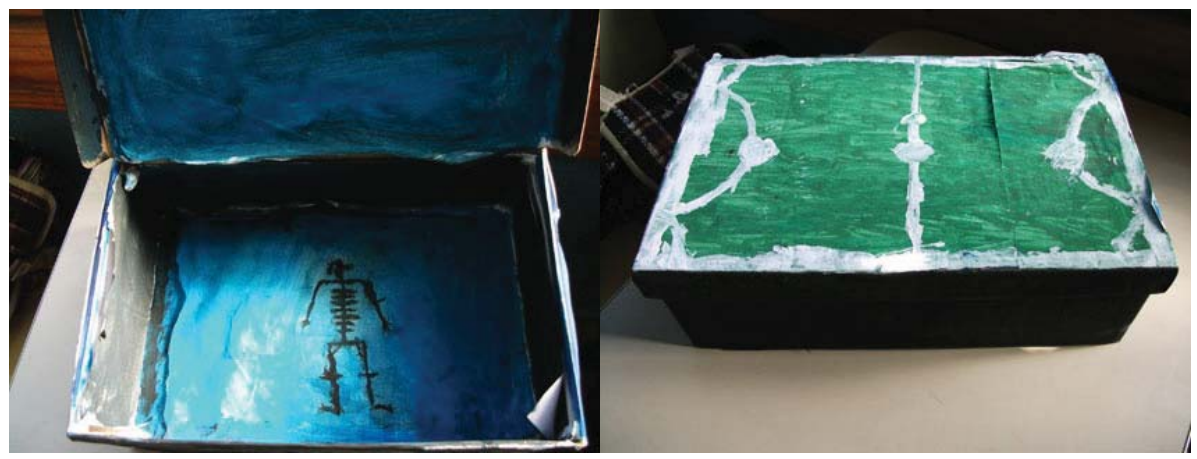

Jogo de Cores

O bonito confundindo-se com o bom, o prazer. Um campo de futebol que não foi feito para ser povoado é apenas objeto de pura contemplação. Não divide espaço com mais nada: laterais planas e pretas. Uma tampa, uma caixa... não, um campo de cor...também não, um campo de futebol! Lugar de encontros, brincadeiras, cabeça longe, momento de extravasar, assim como na arte. Inevitável criar uma transparência entre as duas situações. Qual é a relação entre o azul interior com o prazer do campo de futebol? Um céu invertido, que não mais abriga a despreocupada partida de futebol, mas algo que simboliza o contrário de estar alegre. E aquele preto das laterais já não é mais tão sutil... Uma vez esta caixa aberta, o campo passa a ser outro, o céu também.

Ressalta Benjamin que "a cor pura é o meio da fantasia, a pátria de nuvens da criança que brinca" (2002: 79). Recuperando o efeito "estético-sensorial”, tal como Goethe apreendeu as cores, podemos talvez melhor apreender esta caixa e seu jogo de cores. 
As cores transparentes são ilimitadas em sua luminosidade e em seu obscurecimento - como fogo e água podem ser contemplados como seu ápice e sua profundidade [...] A relação da luz com as cores transparentes é, quando se aprofunda nisso, infinitamente encantadora, e o inflamar das cores e o dissolver-se umas nas outras, e o ressurgir e o desaparecer é como a tomada de fôlego em largas pausas, de eternidade em eternidade, da luz mais intensa até a calma solitária e eterna nas tonalidades mais profundas. As cores opacas, ao contrário, são como flores que não ousam comparar-se com o céu, e, todavia, vinculam-se, de um lado pelo branco, coma franqueza, e de outro pelo negro, com o mal. Mas justamente essas cores são capazes [...] de produzir variações tão agradáveis e efeitos tão naturais que [...] as transparentes, ao final, participam desse jogo apenas como espíritos e servem-se tão somente para ressaltar as opacas. (GOETHE, In: BENJAMIN, 2002: 79-80).

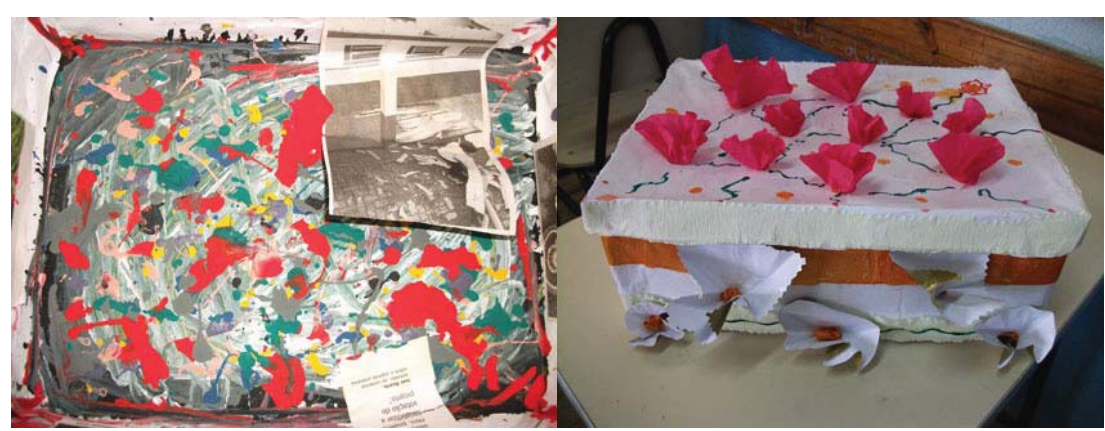

Flores no Caos

No lado bonito. Depois de revestir toda a caixa com papel branco, esconder sua condição de caixa, ela ganha uma outra camada... a primeira se impõe como necessidade, camuflagem do objeto, escondê-lo para ser outro. Já a segunda passa ao colorido dos diferentes materiais. Uma etapa que promove a multiplicação do olhar: não se pode atentar somente para a intercalação de linhas e pontos coloridos da tampa, que formam uma rede... é preciso perceber também as delicadas flores de papel crepom, vermelhas, em contraste com o branco. Ladeando toda a volta da tampa uma fita de papel crepom, também branca. Não contrasta nem altera o campo de cor da tampa, mas o papel crepom empresta sua textura corrugada ao liso. Uma nova fita de papel que, além de sua superfície, oferece a cor... a mesma cor que sutilmente se mostra no interior das flores douradas e brancas, distribuídas pelas laterais da caixa. Estas pequenas bolinhas não estão presas, o papel dobrado (invenção de flores) mantém sua estrutura pela simples dobra, pelo vinco no material... assim, não só pela estética de delicadeza o trabalho ganha este adjetivo, mas pela sua frágil arquitetura.

O feio se guarda dentro. O feio, aqui, é a abstração e algumas cenas de jornal. Uma combinação raivosa de várias cores, com a saliência de um vermelho impositivo. A presença deste vermelho faz par com imagens que retratam a violência na cidade, retiradas de jornais. O que guarda esta caixa? Sob uma frágil beleza, o caos, representado pela abstração e a violência da sociedade contemporânea. Visões de uma Infância... apontamentos de uma infância.

A preocupação da proposta benjaminiana situava-se na esfera de um conhecimento sensível “que não apenas se alimenta daquilo que se apresenta sensível aos seus olhos, mas também consegue apoderar-se do simples saber e mesmo dos inertes como de algo experienciado e vivido" (TIEDEMANN, 2006: 18).

Sob esse aspecto, os conceitos que deram lugar às imagens, pelo esforço do conhecimento, buscam o despertar como “Passagens'. Passagens, que como uma articulação temporal, encontrada por Benjamin nas alegorias de Baudelaire, realizam uma imagem da própria época - a Modernidade dos anos 1920 /30).

Como flores no caos, a infância nos convida a olhar para nossas verdades e incompletudes. Através disso surge a possibilidade de re-direcionarmos nosso olhar ao lugar onde as crianças re-inauguram e renovam sentidos, uma caixa de sapatos guarda assim toda a violência desse desencantando mundo. É a infância nos denunciando nossas incapacidades. Sobre o que nós somos 
e o que nos cerca. Do nosso desajustamento, da nossa insegurança, da nossa não soberania. Uma dimensão da experiência humana que polariza a performance do mundo adulto com a fragilidade da infância. E isso também pode ser melhor apreendida por meio de Gagnebin, que seguindo um ponto de vista benjaminiano, assim ressalta:

\begin{abstract}
Essa fraqueza infantil também aponta para verdades que os adultos não querem mais ouvir: verdade política da presença constante dos pequenos e dos humilhados que a criança percebe, simplesmente, porque ela mesma, sendo pequena, tem outro campo de percepção; ela vê aquilo que o adulto não vê mais, os pobres que moram nos porões cujas janelas beiram a calçada, ou as figuras menores na base das estátuas erigidas para os vencedores. A incapacidade infantil de entender direito certas palavras, ou de manusear direito certos objetos também recorda que, fundamentalmente, nem os objetos nem as palavras estão aí somente à disposição para nos obedecer, mas que nos escapam, nos questionam, podem ser outra coisa que nossos instrumentos dóceis. (GAGNEBIN, 2005: 180).
\end{abstract}

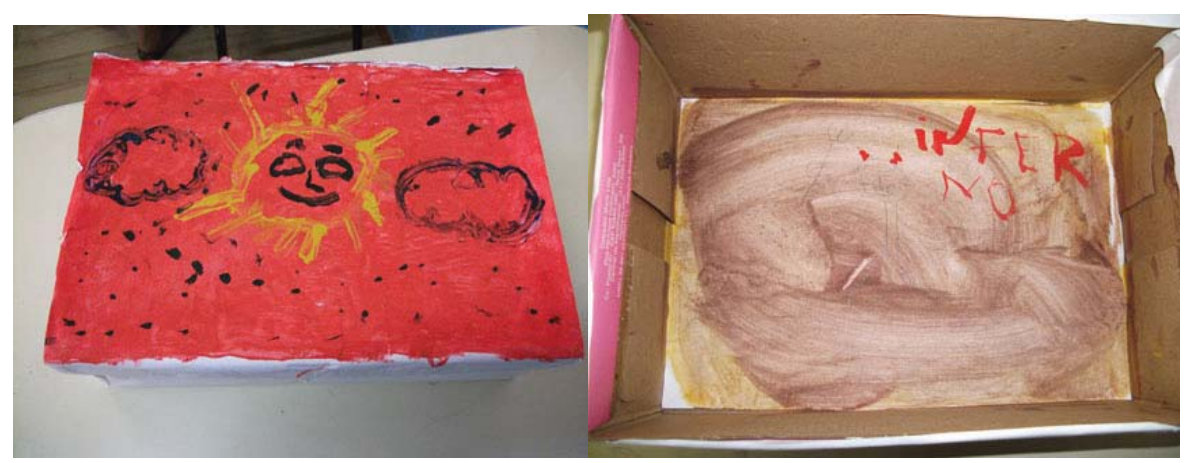

Cada Ideia é um Sol

Se os olhos podem ser "janelas da alma", os olhos da criança, pela caixa, filtram as belezas do universo e nos convidam à contemplação. Num misto de resignação e perda, nossa visão se depara primeiro com um céu de Claudel, "um céu tão azul, que só o sangue é mais vermelho". Para, logo depois, quando buscamos o "fundo desses olhos adoráveis" o que vemos, nitidamente, é outra hora, uma hora que baudelaireando, se faz como "hora vasta, solene, grande como o espaço, sem divisões de minutos nem de segundos, uma hora imóvel que não é marcada nos relógios...".

Rastreando esse tempo, a pintura de criança na caixa é traço, pulsação, caminhos do intangível ao som de um coração batendo pelo inominável-reconhecível. Antimelodia de harmonia complexa, trevas numa parte e do outro lado todos os astros. Em que pesem as imagens descartáveis que teimam fazer do visível mais um ilusório, a infância como um reflexo transparece, como uma atitude de resistência, transformação e criação. Uma caixa que antes guardava sapatos, hoje resguarda faces de outra verdade, metafórica perspectiva que abriga e instala a suspeita, a luz e as sombras, o céu e o inferno, os tempos e os lugares, do que se faz como pura expressão.

Que mais dizer acerca da constelação dessa caixa, se não tentar pontuar por meio de Benjamin com: "Cada idéia é um sol, e se realaciona com outras idéias como os sóis se relacionam entre si" (1984: 59-60). Neste universo de constelações, a criança alegorista segue a pespectiva benjaminina - é aquela que guarda, que não esquece. A criança carrega em "cada lembrança um fragmento", considerando que "a história contínua é uma ilusão". Em cada fragmento, um microcosmo em miniatura, não somente daquilo que pode ser compreendido como sendo o seu destino, mas, fundamentalmente, aquilo que se institui como "promessa utópica de homens melhores, de um mundo feliz, no qual o homem, a natureza e as coisas, liberadas da 'corvéia de serem úteis' viveriam reconciliadas sem a marca da reconciliação" (MATOS, 1989: 89).

CONSIDERAÇÕES FINAIS

Mais do que verificar na infância um espelho incompleto dos valores adultos, encontramos com as crianças outras formas de olhar, de ensinar, de arte. De dois lados o conhecimento. Aprender 
com a Arte, os descaminhos a que ela leva, as possibilidade de dizer, de dizer de si, reinventar o modo de olhar para as coisas, recriando, ao mesmo tempo, as formas de se olhar para a Infância. Aprender com a Infância a procurar estes lugares/momentos de beleza e de feio. Perceber que seus devires falam, sem dizer... Uma caixa pode ser só uma caixa, mas, também, pode ser, pelas crianças, outro sol, ou, quem sabe ainda, uma Pandora esperança nesse desencantado mundo. Deixar perder-se pelo brilho do papel dourado e o cintilante azul... encontrar nas abstrações a quantidade infinita de matizes que a palavra infância pode oferecer... eis o convite... quem dera fosse ao mundo adulto, somente... a aceitação.

\section{REFERÊNCIAS}

AMORIM M. O Pesquisador e Seu Outro: Bakhtin nas Ciências Humanas. São Paulo: Editora Musa, 2001.

BENJ AMI N, W. Origem do Drama Barroco Alemão. São Paulo: Brasiliense, 1984.

Reflexões sobre a criança, o brinquedo e a educação. São Paulo: Ed: 34, 2002.

. Rua de Sentido Único e Infância em Berlim por volta de 1900. Lisboa: Relógio D’água, 1992.

BLOCH, E. O Princípio da Esperança. Rio de Janeiro: EdUERJ : Contraponto,

2005. V.I.

BUSSOLETTI, D. Infâncias Monotônicas: uma rapsódia da esperança: estudo psicossocial e cultural crítico sobre as representações do outro na escrita de pesquisa. Tese de Doutorado. PUC-RS. Porto Alegre, 2007.

FARACCO. C. [et al]. Uma Introdução a Bakhtin. Curitiba: Haiter, 1988.

GAGNEBIN, J.M. Sete aulas sobre linguagem, memória e história. Rio de J aneiro: Imago,2005.

LARROSA, J. Pedagogia Profana: danças piruetas e mascaradas. Belo Horizonte: Autêntica. 2000.

MATOS. O. Os Arcanos do Inteiramente Outro. São Paulo: Brasiliense, 1989.

ROUANET. S. Apresentação. In: Benjamin, W. Origem do Drama Barroco Alemão. São Paulo: Brasiliense, 1984.

TIEDEMANN, R. Introdução a Edição Alemã (1982). In: BENJ AMI N, W. Passagens. Belo Horizonte. Editora UFMG; São Paulo: Imprensa Oficial do Estado de São Paulo, 2006.

Artigo recebido em 07/12/2011

Aprovado em 06/03/2012 